\title{
Breeding of Cymbidium 'Sale Bit' with Bright Yellow Flowers and Floral Scent
}

\author{
Pue Hee Park*, Mummadireddy Ramya, Hye Ryun An, Pil Man Park, and Su Young Lee \\ Floriculture Research Division, National Institute of Horticultural \& Herbal Science, Rural Development \\ Administration, Wanju 55365, Republic of Korea
}

\section{연노란색 꽃의 향기를 지닌 심비디움 ‘Sael Bit’ 육성}

\author{
박부희 ${ }^{*}$ 람야 · 안혜련 · 박필만 · 이수영 \\ 농촌진흥청 국립원예특작과학원 화훼과
}

\begin{abstract}
Oriental Cymbidium 'Sael Bit' cultivar was developed as a hybrid in 2013 by the National Institute of Horticultural \& Herbal Science, Rural Development Administration, Suwon, Korea. This hybrid was developed from a cross between C. faberi 'Ilgyounguhwa' and C. '98CD05-1' in 2002. C. 'Ilgyounguhwa' has a sweet floral scent, and C. '98CD05-1' was obtained from a germplasm from Vietnam. After the cross and successful planting and acclimatization in a greenhouse, 72 seedlings were obtained. In 2007, one line was selected on the basis of flower color, leaf shape, flower stalk, and vigorous growth, and it was named 'Wongyuo F1-37'. The line with the code '02-0428-33' had consistent uniformity and excellent characteristics. The line selected after the evaluation of secondary characteristics was named 'Sael Bit'. This hybrid has bright yellow and green colored petals (GY1B), red spot lips (R53A), and a pleasant fragrance. Flower and plant size of 'Sael Bit' are medium and it has approximately 9.1 flowers per stalk, which can be considered as a good spike habit. Petals and sepals are generally narrow and acute and the inflorescence is erect. Under optimal culture condition, flowers start blooming in late October. (Registration No. 5754)
\end{abstract}

Keywords Cultivar, Orchid, Pot flower, Selection

Received on July 22, 2019. Revised on August 12, 2019. Accepted on August 19, 2019.

* Corresponding Author (E-mail: puehee@korea.kr, Tel: +82-63-238-6842, Fax: +82-63-238-6805)

\section{INTRODUCTION}

Orchid plants are abundantly distributed in tropical regions, and the differentiation of species is varied, reaching 800 genera and 20,000 to 30,000 species (Arditti 1983). Orchids are predominantly divided into tropical orchids and oriental orchids, and the native habitat of tropical orchids is centered on the equator, in the hot and humid tropical and subtropical regions. Many countries in the west region including the U.K have collected orchids since the 18th century, for cultivation and breeding. Oriental orchids, on the other hand, have grown naturally in the temperate regions of the Northeast Asia such as Korea, China, Japan, and Taiwan, since the pre-Christ era (Lee 2006). The Cymbidium genus includes 44 species in total, and it is widely distributed in the regions stretching from Northwest India to China, Japan, Taiwan, Malay Archipelago, to the northeast areas in Australia (Du \& Cribb 1988). The tropical orchid Cymbidium is a well-known winter flower with around two months of flowering period that display around 15 exquisitely beautiful and splendid epiphytic flowers on the first inflorescence. In Korea, most of the orchids were grown to be exported to China but since the anti-graft law by the Xi Jinping government in China, export of orchids to China has been difficult, and the anti-graft law in Korea has also posed growing challenges to the Cymbidium industry. In 2017, the production of Cymbidium was 9.3 billion won, around 3.1 billion won less than the previous year, and the cultivation area was 43.8 ha, moreover showing a reduction by 8.6 ha. The export of orchids in 2017 recorded around 2,352 thousand dollars, and despite of the aggravated conditions both at home and overseas, orchids remained the most exported variety of flowering plants after lily and cactus (MFAFF 2018). In the case of oriental Cymbidium, a large proportion of supply is imported alive, which indicates an urgent necessity to develop a cultivar of oriental Cymbidium to replace 
the imported supply.

Most seeds of the Cymbidium cultivar have been heavily imported from a plant breeding company in Japan for cultivation. With the recent reinforcement of protective measures regarding domestic cultivars in Japan, the demand for unique new cultivars in Korea is rising. Since 2003, Kim et al. (2006, 2007, 2008, 2009, 2010, 2011, 2012, 2013) have developed new cultivars of Cymbidium more acceptable to the domestic cultivation conditions, through the collaboration with the orchid research organizations including the projects of test cultivation in farms, the orchid supply rate has been increased to approximately $18.2 \%$ by 2018 from a more $0.3 \%$ in 2008 . The Cymbidium cultivar distributed in Korea are mostly for the export to China. These cultivars are preferable the red and yellow heavy breeds, with a general lack of scented hybrid cultivars whose growth and development are also active. The present study was conducted to develop an oriental-tropical orchid hybrid cultivar with a scent that enhances the consumer emotional factors, so as to reduce the cost burden in farms from purchasing the seeds of imported cultivars and to replace the imported cultivars for ensuring the competitiveness.

\section{MATERIALS AND METHODS}

To promote a new, scented hybrid Cymbidium cultivar, the Chinese Cymbidium faberi R. and Vietnam germplasm '98CD05-1' were selected among the collected genetic resources and cultivated in a glass house. The growth characteristics were investigated based on the Agricultural Experiment Standards (RDA 2003) of the Rural Development Administration. In January 2002, the resources were used as the maternal and paternal lines for artificial crossing, and the gathered seeds were germinated in vitro in September of the same year. The tissue-culture seedlings with contain approximately $13-15 \mathrm{~cm}$ leaf length were transferred to the greenhouse for transplanting in October the following year. The cultivation and growth characteristics were examined under the conditions of 15 $18^{\circ} \mathrm{C}$ and $10,0001 u x$, using bark as the planting material, at the Cymbidium Greenhouse of National Institute of Horticultural and Herbal Science. The general Cymbidium cultivation methods
(Sakamoto 1996) were followed. The yellow colored lines exhibiting outstanding flower distance and arrangement, as well as blooming, were primarily selected in 2008 and grown in vitro through apical meristem culture. During the period of six years between 2008 and 2013, the tissue-culture plants were analyzed with respect of flower color, shape, number, height, and plant vigor, based on the characterization standards for the application and review of a new Cymbidium cultivar (KSVS 2004), C. 'Ok Hwa' were used as control. The stability per year and consumer preference were investigated, and the color of the plant and each part of the flower were analyzed using the RHS Color Chart (RHS 2001). To comparatively analyze the floral scent intensity, the Electronic Nose ( $\alpha$ FOX 2000, Alpha MOS, France) was used. For pattern analysis, the responses of six sensors were combined and the statistical program Alpha Soft Version 12.38 was used. Each sample was given three repetitive treatments, and among various statistical methods, the discriminant function analysis (DFA) was used to compare the scent intensity between $C$. 'Sael Bit' and $C$. 'Ok Hwa'.

\section{RESULTS AND DISCUSSIONS}

\section{Cultivar growth}

The Cymbidium cultivar 'Sael Bit' was finally selected based on the annual characterization of the '02-0428-33' seedling among the 72 seedlings obtained through the crossing in 2002 between the Chinese Cymbidium faberi R. as maternal line and the Vietnam germplasm '98CD05-1' as paternal line. The seedlings were grown from 2002 to 2007, and those exhibiting outstanding leaf shape as well as flower color and shape were selected for the mass propagation using in vitro seed germination from 2008 to 2012. Following the purification and cultivation, the first and second trials for characterization were conducted. In 2012, the selected cultivar was given the line name 'Won Gyo F1-37', and the investigation on homogeneity, stability, and consumer preference led to the cultivar being recognized as one that shows outstanding blooming and growth characteristics. In 2013, through the deliberation by the Rural Development Administration for Cultivar Regulatory Promotion, the new 
cultivar was named as 'Sael Bit' and after application procedures, the cultivar was registered (Fig. 1). 'Sael Bit' is a Korean word with the meaning the light at the break of day. The name was chosen to send the message of the bright hope of future.

\section{Key Characteristics}

Blooming: $C$. 'Sael Bit' is a cultivar of yellow colored line with light green sepals and petals (RHS, GY1B) and purplish red spots in labellum. For each flower stalk, nine or more flowers bloom as a feature of the maternal line Cymbidium faberi $\mathrm{R}$. The triangular sepal gives stability to the overall shape, and the flower has the sweet scent of maternal line (Table 1). The major volatile component of C. faberi $\mathrm{R}$. is 1,3,7-Octarien in peak area of GC-MS analysis (Kim 2016). The florets attached to the stalk are arranged with such appropriate distance that the overlap between flowers is minimal with beautiful balance. A stock contains 1.7 flower stalks on average, whose length tend to be long with average length of 43.9 $\mathrm{cm}$. For each stalk, approximately 9.1 florets are attached, a good flower setting that leads to relatively easy blooming upon cultivation. Notably, the cultivar has a scent as a hybrid, with the flower shape, color, and size all in a good balance, which led to the strong consumer preference at the cultivar fair (Tables 1, 2). The flowering time for normal cultivation, i.e. without moving to a high altitude area, is late October, as it is for an early to small variety, and the vase life is around two months at ambient temperature between $15-18^{\circ} \mathrm{C}$ although it varies according to temperature (Table 2).

Leaf characteristics: $C$. 'Sael Bit' shows half-erect leaf type, with relatively little drooping that allows easy management during cultivation. The balance between the stalk and leaf shape gives rise to an overall stable shape. The leaves also exhibit

\begin{tabular}{ccccc}
\hline Artificial cross & Selection & $1^{\text {st }}$ characteristic trial & $2^{\text {nd }}$ characteristic trial & $2008 \sim 2011$ \\
& 2002 & $2003 \sim 2007$ & 2012
\end{tabular}

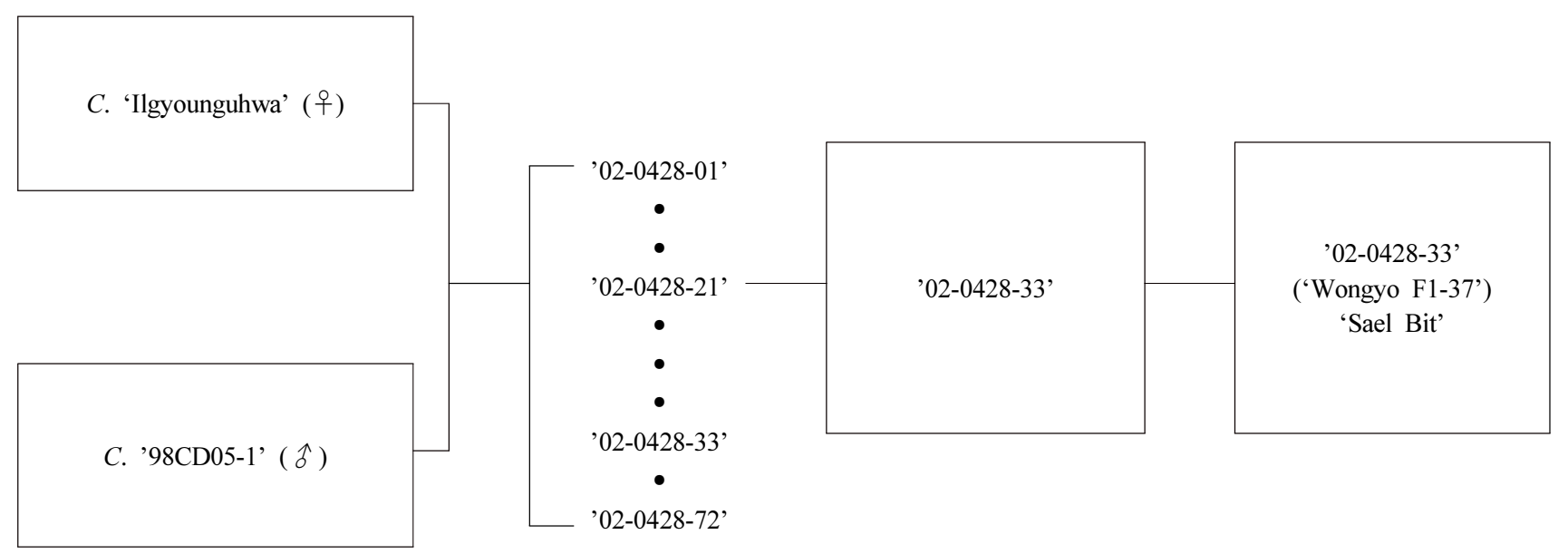

Fig. 1. Pedigree diagram of Cymbidium 'Sael Bit' breeding.

Table 1. Morphological and others characteristics of the Cymbidium cultivar, 'Sale Bit'.

\begin{tabular}{|c|c|c|c|c|c|}
\hline \multirow{2}{*}{ Cultivar } & \multicolumn{2}{|c|}{ Flower } & \multirow{2}{*}{$\begin{array}{c}\text { Inflorescence } \\
\text { attitude }\end{array}$} & \multirow{2}{*}{ Fragrance } & \multirow{2}{*}{ Preference $^{\mathrm{y}}$} \\
\hline & Color $(\text { Lip })^{z}$ & Shape & & & \\
\hline Sale Bit & GY1B (R53A) & Slightly incurved & Erect & Strong & $4.1 \pm 1.1$ \\
\hline Ok Hwa (Control) & Y2B (RP63C) & Slightly incurved & Erect & Weak & $3.7 \pm 0.4$ \\
\hline
\end{tabular}

${ }^{\mathrm{z}}$ The Royal Horticultural Society color chart.

${ }^{\mathrm{y}}$ Preference evaluation was taken at the Cymbidium exhibition held at National Institute Horticultural and Herbal Science (NIHHS) in 2012. Poor (1) - Excellent (5). 
excellent light transmission and vigorous growth. The flowering time of the control cultivar $C$. 'Ok Hwa' is from September, whereas that of the cultivar $C$. 'Sael Bit' is late October. Compared to the control, $C$. 'Sael Bit' shows longer leaf length with $59.7 \mathrm{~cm}$, which is shorter than $80 \mathrm{~cm}$ of average medium variety. The leaf width is relatively narrow at $1.4 \mathrm{~cm}$, and an additional benefit comes from the weak twist at the tip of leaves (Table 3).

Scent characteristics: To comparatively analyze the floral scent intensity, the DFA was performed. The PCA and DFA are frequently used to analyze the intensity and pattern of flower scent. PCA indicates how far each component has been separated, and the farther away from the control (Air), the stronger the scent. DFA is used in the analysis of unknown samples, and it allows easy identification of the pattern to which the strong scent belongs (Park et al. 2014). The result of the scent analysis using DFA showed that, compared to the control $C$. 'Ok Hwa', the figures for $C$. 'Sael Bit' appeared at an area farthest from the control, which suggested that the scent of $C$. 'Sael Bit' was stronger than $C$. 'Ok Hwa' (Fig. 3).

\section{Precautions for cultivation}

For the cultivation of $C$. 'Sael Bit', high-density culture should be avoided, while making sure the plants are apart at steady intervals with adequate amount of light transmission during the period of growth. The general Cymbidium cultivation methods can be followed, and for summer cultivation, an adequate shading is needed to prevent more than ten consecutive days of high temperature above $30^{\circ} \mathrm{C}$. During the rainy season, with high temperature and moisture, ventilation should be thorough to prevent diseases.
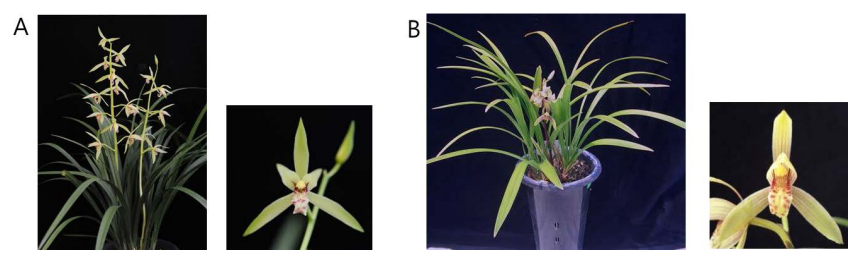

Fig. 2. Flower characteristics of newly bred Cymbidium 'Sael Bit' (A) and control C. 'Ok Hwa' (B).

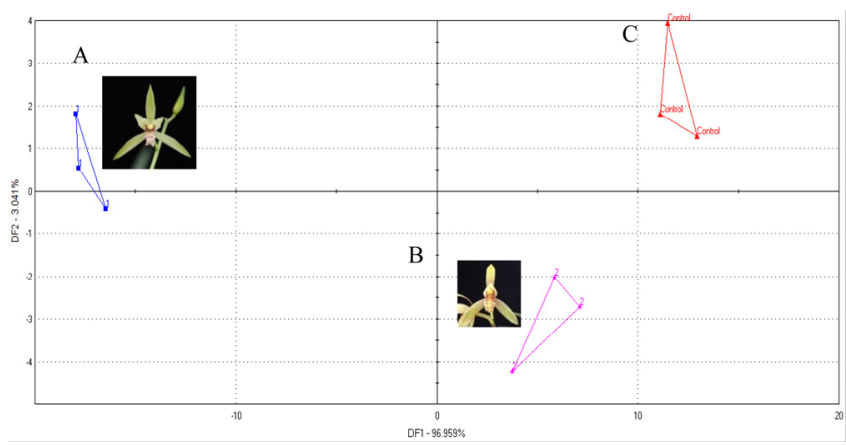

Fig. 3. Two-dimensional Discriminant Factorial Analysis score plots generated by the electronic nose system. Cymbidium 'Sael Bit' (A), C. 'Ok Hwa' (B), and air (C).

Table 2. Flower characteristics of the Cymbidium cultivar, 'Sael Bit'.

\begin{tabular}{|c|c|c|c|c|c|c|}
\hline \multirow{2}{*}{ Cultivar } & \multicolumn{2}{|c|}{ Flower $(\mathrm{cm})$} & \multicolumn{3}{|c|}{ Inflorescence } & \multirow{2}{*}{ Blooming date } \\
\hline & Width & Length & Length $(\mathrm{cm})$ & No. of flowers & The number & \\
\hline Sael Bit & $5.7 \pm 0.6^{\mathrm{z}}$ & $4.2 \pm 0.5$ & $43.9 \pm 4.8$ & $10.8 \pm 2.0$ & $1.7 \pm 1.4$ & October \\
\hline Ok Hwa (Control) & $3.7 \pm 0.7$ & $3.1 \pm 0.3$ & $23.4 \pm 2.2$ & $15.5 \pm 3.1$ & $7.2 \pm 0.4$ & November \\
\hline
\end{tabular}

${ }^{\mathrm{z}}$ Mean \pm standard deviation of 15 plants.

Table 3. Leaf characteristics of the Cymbidium cultivar, 'Sael Bit'.

\begin{tabular}{cccccc}
\hline \multirow{2}{*}{ Cultivar } & Plant size & \multicolumn{4}{c}{ Leaf } \\
\cline { 3 - 6 } & & Length $(\mathrm{cm})$ & Width $(\mathrm{cm})$ & Number & Twisting \\
\hline Sael Bit & Small & $59.7 \pm 5.3^{\mathrm{y}}$ & $1.4 \pm 0.3$ & $8.3 \pm 2.1$ & Weak \\
Ok Hwa (Control) & Small & $45.6 \pm 2.5$ & $1.6 \pm 0.2$ & $7.7 \pm 1.5$ & Weak \\
\hline
\end{tabular}

${ }^{\mathrm{z}}$ Plant size is based on leaf length. Small size is below around $60 \mathrm{~cm}$ of leaf length.

${ }^{\mathrm{y}}$ Mean \pm standard deviation of 15 plants. 


\section{Utility}

The application for the cultivar $C$. 'Sael Bit' was made on July 8, 2013, based on the Seed Industry Act, and following the deliberation for cultivation by the Korea Seed and Variety Service, the Plant Variety Protection Right for the cultivar was registered (No. 5754) on November 9, 2015. Through the technology transfer in 2016 to a seed manufacturing company, the cultivar was mass propagated and supplied to the farms for cultivation.

\section{ACKNOWLEDGEMENTS}

This study was supported by the Rural Development Administration, Collaborative Research Project (No. PJ01183201).

\section{REFERENCES}

1. Arditti J. 1983. Orchid biology: Reviews and perspectives. Cornell University Press, London. pp. 233-239.

2. Du PD, Cribb P. 1988. The genus Cymbidium. Timber Press, Oregon. pp. 50-194.

3. Kim MS, Lee YR, Jung MI, Song JS, Kim JY. 2006. A new Cymbidium hybrid 'Beauty Princess' with red purple petals and medium plant size. Korean J Breed Sci 38: 205-206.

4. Kim MS, Lee YR, Jung MI, Kim JY, Song JS. 2007. A new Cymbidium hybrid 'Bright Evening' with brownish yellow petals. Korean J Breed Sci 39: 389-390.

5. Kim MS, Cho HR, Rhee HK, Lim JH, Choi SY, Kim YJ. 2008. A new cultivar Cymbidium 'White Princess' with white color and vigorous growth. Flower Res J 16: 295-298.

6. Kim MS, Cho HR, Rhee HK, Lim JH, Lee YR, Shin HK. 2009. A new Cymbidium variety "Yellow Evening" with brownish yellow flower color on red spot lip and medium plant. Korean J Breed Sci 41: 358-362.

7. Kim MS, Cho HR, Rhee HK, Lim JH, Shin HK. 2010. Development of new Cymbidium variety 'White Girl' medium type, red lip flower. Hort Environ Biotechnol 51: 235-238.

8. Kim MS, Cho HR, Rhee HK, Lim JH, Shin HK. 2011. A new Cymbidium cultivar 'Orange Bowl' with orange colored flower and medium sized plant. Kor J Hort Sci Technol 29: 651-654.

9. Kim MS, Rhee JH, Shin HK, Lim JH. 2012. A medium sized Cymbidium 'Pink Glory' with brilliant pink flowers. Kor J Hort Sci Technol 30: 613-616.

10. Kim MS, Rhee JH, Park SK, Shin HK, Jung HY, Lim JH. 2013. A light green colored Cymbidium cultivar 'Green Honey' with medium and small sized plant for pot flower. Korean J Breed Sci 45: 183-187.

11. Kim MS, Lee YR, Park PH, Lee IG, Jung BN, Han KS, Kang TJ. 2013. Assistant agricultural technology 183, Cymbidium. Rural Development Administration (RDA). Suwon, Korea.

12. Kim SM, Jang EJ, Hong JW, Song SH, Park CH. 2016. A comparison of functional fragrant components of Cymbidium (Oriental Orchid) Species. Kor J Hort Sci Technol 23: 331-341.

13. Korea Seed and Variety Service (KSVS). 2004. Guidelines for the conduct of tests for distinctness, uniformity and stability of Cymbidium. Anyang, Korea. pp. 1-54.

14. Lee JS. 2006. Orchids of Korea, Hyangmoonsa, Korea. pp. 10-13.

15. Ministry of Food, Agriculture, Forestry and Fisheries (MFAFF). 2018. 2017 status of cultivation in flower crops. MFAFF, Korea.

16. Park PH, Kim MS, Lee YR, Park PM, Lee DS. 2014. Fragrance pattern analysis of major floricultural crops using electronic nose, Flower Res J 22: 235-239.

17. Rural Development Administration (RDA). 2003. Manual for agricultural investigation. Suwon, Korea.

18. Royal Horticultural Society (RHS). 2001. The royal horticultural society's color chart. Royal Hort Soc, London, UK.

19. Sakamoto S. 1996. Orchid/Cactus/Succulents, Agricultural Technology, Sec.12. Rural Culture Association Japan, Tokyo, Japan pp. 135-140. 